\title{
Editorial: the European Reference Index for the Humanities
}

7 he aim of the European Reference Index for the Humanities (ERIH), as set out on the website of the Arts and Humanities Research Council (http://www.ahrc.ac.uk/About/Policy), is 'to create a list of significant arts and humanities journals in Europe'. It is run by the European Science Foundation (ESF). The AHRG is complicit in this scheme, which has 'expert panels' in the fashion of those other acronyms familiar to British academics, RAE and QAA. The aim is to help 'identify excellence in Humanities scholarship and become a useful reference tool for scholars'. After this crisp start to the AHRC's presentation of the ERIH, one detects a certain defensiveness setting in, as the AHRG 'strongly advises against the use of the ERIH outcomes as the basis for the assessment of individual candidates for employment or funding'. As to the assessment and allocation of research funding, 'the outcomes of the ERIH project do not and will not feature in this process'.

Tudor scholars will be familiar with similar reservations expressed by the Convocation of Canterbury in I53I, when Henry VIII demanded that they recognise something that they had previously unaccountably overlooked, that he was the Supreme Head of the Church in England. Convocation complied, with the rider 'insofar as the Law of Christ allows'. It made not a whit of difference to Henry's plans, and it is likely that the AHRC will find its principled caveats have a similar purchase on the intentions of the ESF. One notes that it is the European Science Foundation which has dreamt up this proposal, which might have its possible uses in hard science (that is for practitioners of scientific research to decide), but which is grotesquely inappropriate for the variety of journals which serve the academic communities grouped under the banner of humanities.

Already influential bodies of humanities scholars have taken a stand against the misconceived scheme. Eloquent denunciations are to be found in an editorial of our sister-journal the Scottish Historical Review lxxxviii (2009), I-2, and in an editorial statement published inter alia in the British fournal for the History of Science xlii (2009), I-4, representing an impressive array of no 
fewer than fifty-three journals dealing with the history of science in half a dozen languages. All these journals have asked the compilers of the ERIH to remove their journals' titles from the listing. It is hardly necessary to rehearse the arguments made, apart from noting the point obvious to anyone with a humanities background that 'Great research may be published anywhere and in any language'. The Fournal of Ecclesiastical History, with the emphatic and enthusiastic backing of its Advisory Editorial Board meeting in September 2009, endorses everything that has been said already about the ERIH, and has similarly told the compilers of the ERIH that it wishes to have nothing to do with the listing. We hope that with one acronym less to plague us we can now continue with the business of exploring our academic disciplines in a way which may best contribute to the health of our common culture.

Diarmaid MacGulloch James Carleton Paget, EDITORS 